\title{
Structural and FTIR Spectroscopic Studies of Mg-Zn Ferrite Nanoparticles Synthesized by Co-Precipitation Technique
}

\author{
S. B. Singh ${ }^{1}$, Ch. Srinivas ${ }^{2}$ \\ ${ }^{1}$ Department of Physics, Government Polytechnic, Tadepalligudem 534101, India, \\ ${ }^{2}$ Department of Physics, Sasi Institute of Technology and Engineering, Tadepalligudem 534101, India,
}

\begin{abstract}
A$ series of co-precipitated $\mathrm{Mg}_{x} \mathrm{Zn}_{1-x} \mathrm{Fe}_{2} \mathrm{O}_{4}(x=0.5,0.6,0.7)$ ferrite nanoparticles have been synthesized followed by annealing at a temperature of $200{ }^{\circ} \mathrm{C}$. The results obtained from XRD and IR analysis are reported. XRD patterns confirm the formation of cubic spinel phase of ferrite samples along with secondary phase of $\alpha-\mathrm{Fe}_{2} \mathrm{O}_{3}$ and $\mathrm{MgO}$. Both lattice parameter and crystallite size decreased with the substitution of $\mathrm{Mg}^{2+}$. FTIR spectra present the characteristic peaks of spinel structure. This paper reports the structural results obtained from XRD and FTIR studies and the results are analyzed presuming core-shell interactions and cation redistribution.
\end{abstract}

Keywords: XRD; FTIR; ferrites; nanoparticles.

\section{Introduction}

Synthesis and characterization of spinel ferrites at nanoscale have drawn much attention because nanoparticles with large surface to volume ratios have enhanced magnetic, electrical, optical properties which in turn found potential applications in magnetic fluid, high density data storage, medical diagnostics, etc. [1]. Mg-Zn ferrite is one of the promising candidates which has been used in electronics applications. Besides that, due to low magnetic anisotropy this can be suitable for cancer treatment by hyperthermia [2]. $\quad \mathrm{Mg}$ $\mathrm{Zn}$ ferrite is a mixed ferrite of $\mathrm{Mg}$-ferrite and $\mathrm{Zn}$-ferrite. $\mathrm{Mg}$ occupies octahedral (B) sites and $\mathrm{Zn}$ occupies tetrahedral (A) sites in the spinel structure with the formula unit $\left(\mathrm{Zn}^{2+}{ }_{1-}\right.$ $\left.{ }_{x} \mathrm{Fe}^{3+}{ }_{x}\right)\left[\mathrm{Mg}^{2+}{ }_{x} \mathrm{Fe}^{3+}{ }_{2-\mathrm{x}}\right] \mathrm{O}_{4}$. [3].

Spinel ferrites at nanoscale have been synthesized employing various chemical routes such as sol-gel [4], reverse micelle method [5], ultra sound irradiation [6], hydrothermal method, etc. [7]. Among all these methods coprecipitation method is highly preferable for preparation of ferrites because of easy preparation, composition flexibility, homogeneity, etc. [8].

In the present study a series of $\mathrm{Mg}_{\mathrm{x}} \mathrm{Zn}_{1-\mathrm{x}} \mathrm{Fe}_{2} \mathrm{O}_{4}$ ( $\mathrm{x}=0.5,0.6$, $0.7)$ ferrite nanoparticles have been synthesized using co-precipitation method and the samples were annealed at $200{ }^{\circ} \mathrm{C}$. X-ray diffraction (XRD), scanning electron microscopy (SEM) and Fourier transform infrared spectroscopy (FTIR) were employed for characterization. In the present paper the results of structural and FTIR analysis are reported and are incorporated presuming core-shell interactions and cation redistribution.

\section{Experimental}

High purity magnesium chloride $\left(\mathrm{MgCl}_{2} 6 \mathrm{H}_{2} \mathrm{O}\right)$, zinc chloride $\left(\mathrm{ZnCl}_{2}\right)$ and ferric chloride $\left(\mathrm{FeCl}_{3} 6 \mathrm{H}_{2} \mathrm{O}\right)$ were taken as starting materials to prepare ferrite nanoparticles by co-precipitation technique [9]. Each material was weighed separately in stoichiometric ratio and dissolved in a suitable quantity of de-ionized water to obtain $0.5 \mathrm{M}$ solutions. The cationic solutions were mixed thoroughly using a magnetic stirrer for complete dissolution and heated to $60^{\circ} \mathrm{C}$. A NaOH solution of $0.4 \mathrm{M}$ concentration was prepared and heated to $60{ }^{\circ} \mathrm{C}$ and quickly transferred into the hot cationic solution while maintaining the stirring and heating till complete precipitation was occurred. Heating of the precipitate in its alkaline condition was continued at a soaking temperature of $100{ }^{\circ} \mathrm{C}$ for $1 \mathrm{~h}$. Stirring was further continued for $12 \mathrm{~h}$ for complete aging. The precipitated particles were washed several times and dried at $80{ }^{\circ} \mathrm{C}$ for 2 days. The ferrite powders were pressed under a pressure of $50 \mathrm{MPa}$ into pellets of uniform diameter of $1.5 \mathrm{~cm}$ and a varying thickness of $2 \mathrm{~mm}$ to $3 \mathrm{~mm}$. The pellets were heat treated at $200{ }^{\circ} \mathrm{C}$ in air for $2 \mathrm{~h}$ and were ground into fine powder in an agate mortar. The powders were characterized by XRD, SEM and FTIR techniques.

An INELXRG 3000 powder diffractometer was employed to obtain the X-ray diffraction patterns of the samples using Co $K_{\alpha}(1.78901 \AA)$ radiation.

A Carl Zesis EVOMA15 scanning electron microscope was employed to check the morphology of the samples.

IR spectra were recorded in the range $400 \mathrm{~cm}^{-1}$ to $4000 \mathrm{~cm}^{-}$ ${ }^{1}$ using Perkin Elmer spectrometer.

\section{Results and Discussion}

$\mathrm{X}$-ray diffraction analyses have been performed on the series of $\mathrm{Mg}_{\mathrm{x}} \mathrm{Zn}_{1-\mathrm{x}} \mathrm{Fe}_{2} \mathrm{O}_{4}(\mathrm{x}=0.5,0.6,0.7)$ ferrite samples to study their structural phase and the respective XRD patterns are given in Fig.1. The XRD patterns reveal the cubic spinel structure of samples along with secondary phases of 


\section{International Journal of Science and Research (IJSR) \\ ISSN (Online): 2319-7064}

Index Copernicus Value (2013): 6.14 | Impact Factor (2014): 5.611

$\alpha-\mathrm{Fe}_{2} \mathrm{O}_{3}$ and $\mathrm{MgO}$. These secondary phases were also observed in other ferrites at low annealing temperatures $[10,11]$. The diffraction planes are analyzed with powder software and the planes are indexed as (220), (311), (400), (422), (511) and (440) which are well matched with the earlier reports [12]. The broadening and low intensity of diffraction peaks is attributed to presence of ultrafine particles in the samples. The structural and microstructural parameters were calculated using the following relations. The average lattice constant values $(a)$ were obtained using $2 \theta$ values of the most intense peaks using Bragg's diffraction [13] condition, given by

$$
a=\frac{\lambda \sqrt{h^{2}+k^{2}+l^{2}}}{2 \sin \theta}
$$

The average crystallite sizes are calculated with full width at half maximum of most intense peaks using Debye-Sherrer's [13] equation, given by

$$
D=\frac{K \lambda}{\beta \cos \theta}
$$

where $K$ is shape factor taken as $0.89, \lambda$ is the $\mathrm{X}$-ray wavelength used and $\beta$ is full width at half maximum intensity taking into account of instrumental broadening.

The X-ray density [13] has been calculated using the relation

$$
\rho_{x}=\frac{8 M}{N_{A} a^{3}}
$$

where $M$ is molecular weight of the ferrite sample, $N_{A}$ is Avogadro's number and $a$ is experimental lattice constant.

The lattice strain was estimated from the following derived relation modifying the Williamson and Hall equation [14]

$$
\eta=\frac{2 d|K-1|}{D}
$$

where $\mathrm{d}$ is lattice spacing for (311) planes, $D$ is average crystallite size and $K(0.89)$ is shape factor.

The calculated values of lattice parameter $(a)$, crystallite size $(D)$, X-ray density $\left(\rho_{\mathrm{x}}\right)$ and lattice strain $(\eta)$ are summarized in Table.1. The values of lattice parameter are in between the reported values of lattice parameters of $\mathrm{MgFe}_{2} \mathrm{O}_{4}$ [15] and $\mathrm{ZnFe}_{2} \mathrm{O}_{4}$ [16] and it was observed that the lattice parameter increases monotonically with the substitution of $\mathrm{Mg}^{2+}$, which is attributed to smaller ionic radius of $\mathrm{Mg}^{2+}(0.67 \AA)$ compared to $\mathrm{Zn}^{2+}(0.74 \AA)$. The similar observations were reported for other spinel ferrites $[17,18]$. The crystallite size decreases with increase of $\mathrm{Mg}^{2+}$ ion concentration, resulting in the increase of lattice strain. The variations in lattice parameter and crystallite size follow the Vegard's law [19] as shown in Fig 2. It was observed that the experimental density decreases with increase of $\mathrm{Mg}^{2+}$ ion concentration. The variation of experimental density depends upon molecular weight of ferrite in spite of decrease in lattice parameter. In the present study the substitution of low atomic mass of $\mathrm{Mg}^{2+}$ ion (24.3g) substantially decrease the molecular weight of ferrite which was resulted in the decrease of density.

The SEM micrographs of annealed ferrites of $\mathrm{Mg}_{\mathrm{x}} \mathrm{Zn}_{1-\mathrm{x}} \mathrm{Fe}_{2} \mathrm{O}_{4}$ $(\mathrm{x}=0.5,0.6,0.7)$ at $200{ }^{\circ} \mathrm{C}$ are shown in Fig.3. The nature of SEM micrographs reveals the small sizes of ferrite
Figure 1: $\mathrm{XRD}$ patterns of $\mathrm{Mg}_{\mathrm{x}} \mathrm{Zn}_{1-\mathrm{x}} \mathrm{Fe}_{2} \mathrm{O}_{4}(\mathrm{x}=0.5,0.6,0.7)$

Figure 2: Plot of lattice parameter and crystallite sizes.

Table 1: Lattice parameter $(a)$, crystallite size $(D)$, experimental density $\left(\rho_{x}\right)$ and lattice strain $(\eta)$.

\begin{tabular}{|c|c|c|c|c|}
\hline$x$ & $a(\AA)$ & $D(\mathrm{~nm})$ & $\rho_{x}\left(\mathrm{~g} / \mathrm{cm}^{3}\right)$ & $\eta\left(\times 10^{-3}\right)$ \\
\hline 0.5 & 8.442 & 8.4 & 4.869 & 6.65 \\
\hline 0.6 & 8.425 & 5.1 & 4.807 & 10.86 \\
\hline 0.7 & 8.420 & 2.3 & 4.724 & 26.69 \\
\hline
\end{tabular}

nanoparticles. These small particles are agglomerated into large clusters as observed from SEM micrographs. Similar observations were also reported by other researchers [20]. The close examination reveals the distribution of particles in different sizes which is ascribed to the nature of grain boundaries of particles that requires different surface energies needed for grain growth.

Fourier transform infrared spectroscopy has been employed to observe the structural variations and spinel phase of ferrite systems. The two vibrational bands, one is higher vibrational frequency $\left(v_{1}\right)$ in the range of $600-500 \mathrm{~cm}^{-1}$ and the other one is lower vibrational frequency $\left(v_{2}\right)$ in the range of $450-350 \mathrm{~cm}^{-1}$, are the characteristic bands of cubic spinel structure [21]. The higher vibrational frequency $\left(v_{1}\right)$ is assigned to $\mathrm{Fe}^{3+}-\mathrm{O}^{2-}$ stretching vibrations at tetrahedral site (A) and the lower vibrational frequency $\left(v_{2}\right)$ 


\section{International Journal of Science and Research (IJSR) ISSN (Online): 2319-7064}

Index Copernicus Value (2013): 6.14 | Impact Factor (2014): 5.611
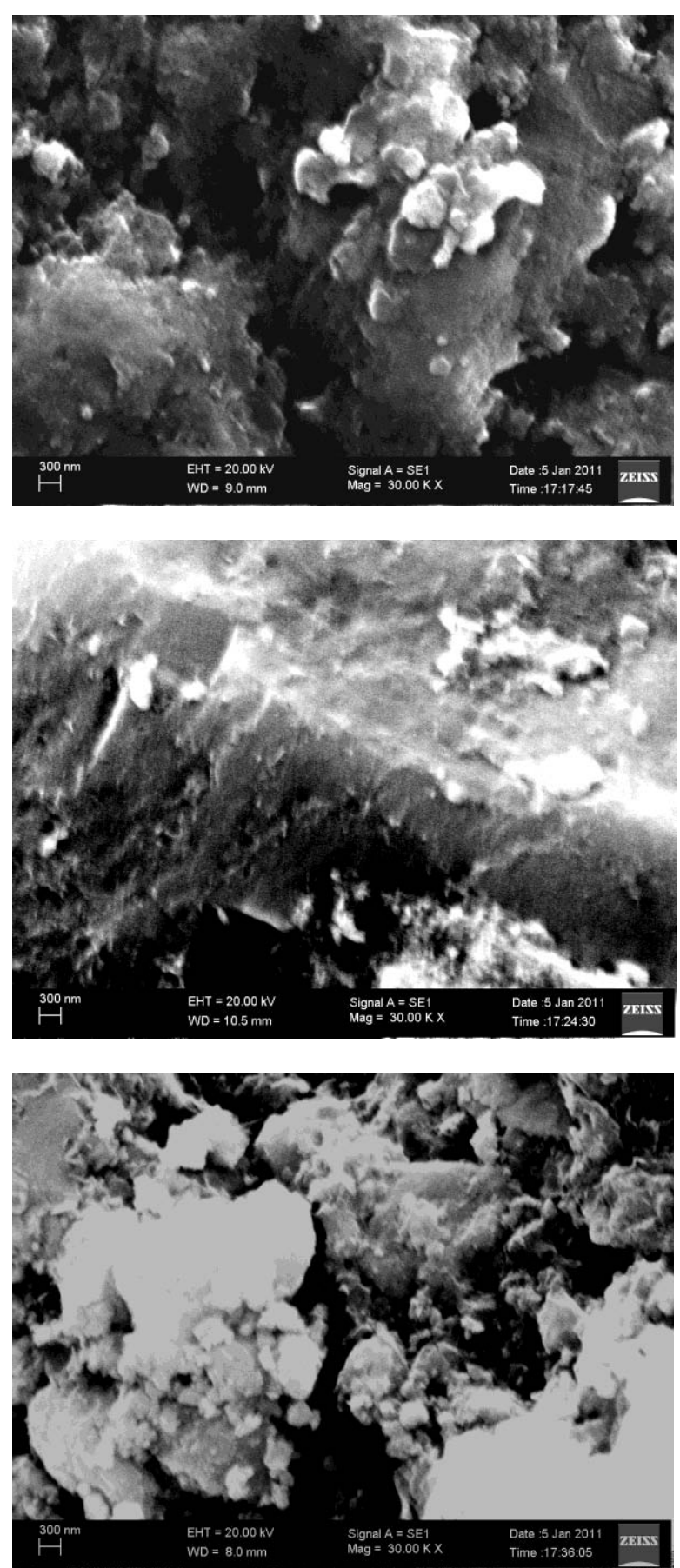

Figure 3: $\mathrm{SEM}$ micrographs of $\mathrm{Mg}_{\mathrm{x}} \mathrm{Zn}_{1-\mathrm{x}} \mathrm{Fe}_{2} \mathrm{O}_{4}(\mathrm{x}=0.5,0.6$, $0.7)$

is assigned to $\mathrm{Fe}^{3+}-\mathrm{O}^{2-}$ stretching vibrations at octahedral site (B).

The FTIR spectra of $\mathrm{Mg}_{\mathrm{x}} \mathrm{Zn}_{1-\mathrm{x}} \mathrm{Fe}_{2} \mathrm{O}_{4}(\mathrm{x}=0.5,0.6,0.7)$ are shown in Fig.4. The tetrahedral and octahedral vibrational frequencies $\left(v_{1}\right.$ and $\left.v_{2}\right)$ along with tetrahedral and octahedral force constants $\left(K_{T}\right.$ and $\left.K_{O}\right)$ are listed in Tab.2. It was observed that the both tetrahedral and octahedral vibrational frequencies are shifted towards the higher frequencies with increase in $\mathrm{Mg}^{2+}$ ion concentration, which are ascribed to increase in force constants and contraction of $\mathrm{Fe}^{3+}-\mathrm{O}^{2-}$ bond lengths at both $\mathrm{A}$ and $\mathrm{B}$ sites. This supports the observed decrease in lattice constant. T. Slatineanu et al [22] observed similar variation in $\mathrm{Zn}$ ferrites substituted with $\mathrm{Ni}$.

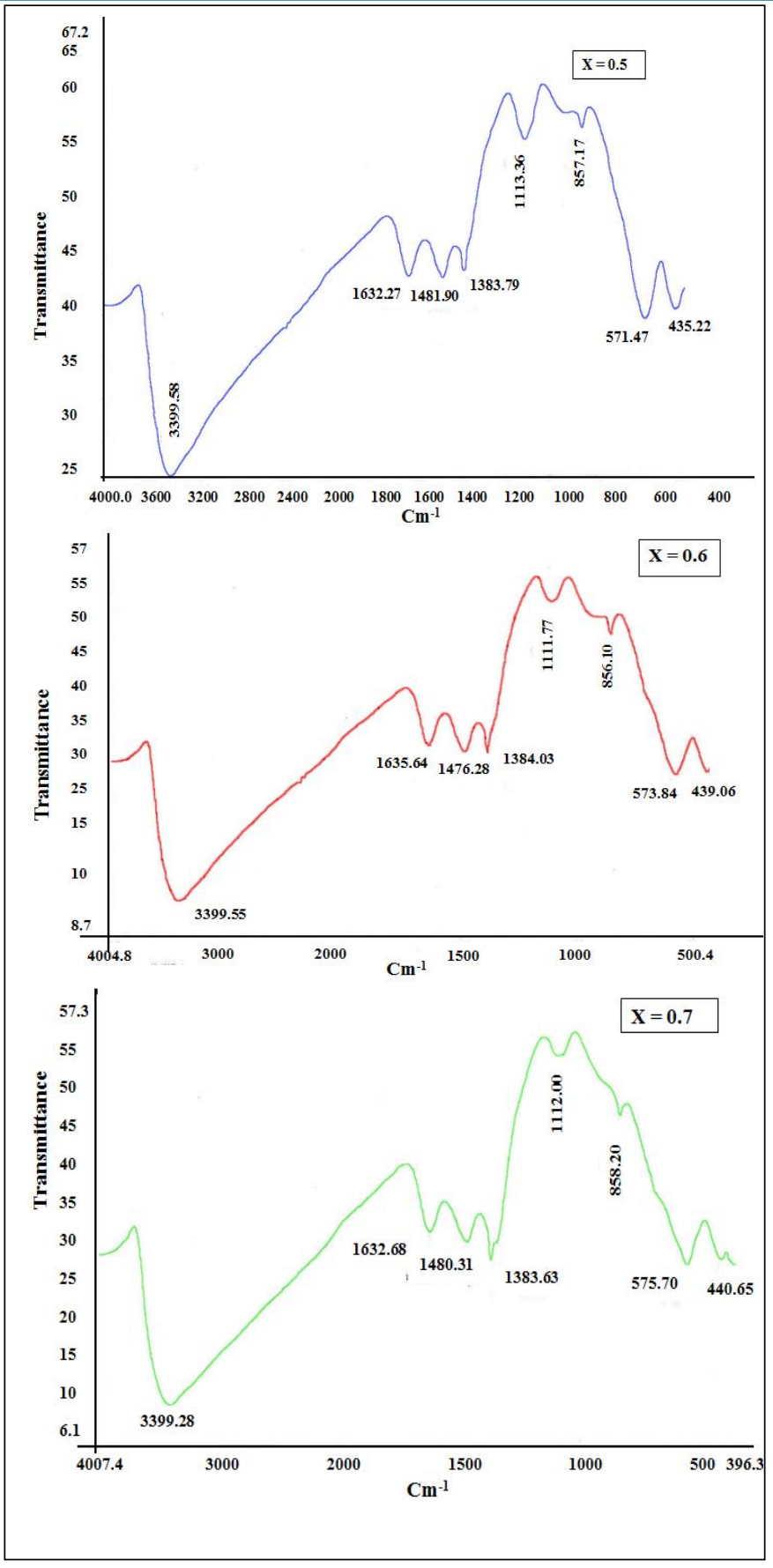

Figure 4: FTIR spectra of $\mathrm{Mg}_{\mathrm{x}} \mathrm{Zn}_{1-\mathrm{x}} \mathrm{Fe}_{2} \mathrm{O}_{4}(\mathrm{x}=0.5,0.6,0.7)$

Table 2: Tetrahedral, octahedral vibrational frequencies ( $v_{1}$ and $v_{2}$ ) and force constants $\left(\mathrm{K}_{\mathrm{T}}\right.$ and $\left.\mathrm{K}_{\mathrm{O}}\right)$

\begin{tabular}{|c|c|c|c|c|}
\hline$x$ & $v_{1}\left(\mathrm{~cm}^{-1}\right)$ & $v_{2}\left(\mathrm{~cm}^{-1}\right)$ & $K_{T}\left(\right.$ dyne/ $\left.\mathrm{cm}^{2}\right)$ & $K_{O}\left(\right.$ dyne $\left./ \mathrm{cm}^{2}\right)$ \\
\hline 0.5 & 571.47 & 435.22 & 239.25 & 138.76 \\
\hline 0.6 & 573.84 & 439.06 & 241.24 & 141.19 \\
\hline 0.7 & 575.70 & 440.65 & 242.81 & 142.25 \\
\hline
\end{tabular}

variation in $v_{2}$. The increase in $v_{1}$ and $v_{2}$ in the present series is attributed to random distribution of cations in tetrahedral (A) and octahedral (B) sites against their normal preference. The broad band around $3400 \mathrm{~cm}^{-1}$ can be assigned to hydroxyl group and the bands around $1630-1384 \mathrm{~cm}^{-1}$ and $970-880 \mathrm{~cm}^{-1}$ are assigned to in-plane and out-plane of O-H vibration $[24,25]$. The remaining bands are probably due to combinational frequencies or overtones. M.A. Gabal et al [23] reported the increase in $v_{1}$ and random 


\section{International Journal of Science and Research (IJSR) \\ ISSN (Online): 2319-7064}

Index Copernicus Value (2013): 6.14 | Impact Factor (2014): 5.611

\section{Conclusions}

$\mathrm{Mg}_{\mathrm{x}} \mathrm{Zn}_{1-\mathrm{x}} \mathrm{Fe}_{2} \mathrm{O}_{4}(\mathrm{x}=0.5,0.6,0.7)$ ferrite nanoparticles were prepared successfully using co-precipitation technique. XRD patterns confirm the formation of spinel phase of ferrite samples along with secondary phases. Both crystallite sizes and lattice parameters are decreased with increase in $\mathrm{Mg}^{2+}$ ion concentration. The variation in $v_{1}$ and $v_{2}$ is ascribed to random variation of cations in the spinel structure. The method of preparation and nature of additives influence the cation distribution affecting the structural parameters.

\section{References}

[1] M. A. Gabal, Y. M. AlAngari "Effect of chromium ion substitution on the electromagnetic properties of nickel ferrite" Mater.Chem.Phys.118(2009) 153-160.

[2] P. Pulišová, J. Kováč, A. Voigt, P. Raschman "Structure and magnetic properties of $\mathrm{Co}$ and $\mathrm{Ni}$ nano-ferrites prepared by a two step direct microemulsions synthesis" J. Magn. Magn. Mater 341(2013) 93-99.

[3] R.A. Waldron, "Ferrites: An Introduction for Microwave Engineers", D. Van Nostrand Company Ltd., London, 1961.

[4] S. Ramesh, B. Chandra Sekhar, P. S. V. Subba Rao, B. Parvatheeswara Rao "Microstructural and magnetic behavior of mixed Ni-Zn-Co and Ni-Zn-Mn ferrites" Ceram. Int 40 (2014) 8729-8735.

[5] S.Gubbala, H. Nathani, K.Koizol, R.D.K.Misra "Magnetic properties of nano crystalline Ni-Zn, Zn-Mn and $\mathrm{Ni}-\mathrm{Mn}$ ferrites synthesized by reverse micelle technique" Physica B348(2004)317-328.

[6] Hanif A.Choudhury, Amit Choudhary, Manickam Siva Kumar, Vijayanand S. Moholka "Mechanistic investigation of the sonochemical synthesis of zinc ferrite" Ultrason. Sono. Chem. 20(1)(2013)294-302.

[7] Zhongzhu Wang, Yanyu Xie, Peihong Wang, Yongqing Ma, Shaowei Jin, Xiansong Liu, Microwave anneal effect on magnetic properties of $\mathrm{Ni}_{0.6} \mathrm{Zn}_{0.4} \mathrm{Fe}_{2} \mathrm{O}_{4}$ nanoparticles prepared by conventional hydrothermal method" J. Magn. Magn. Mater. 323(2011) 3121-3125.

[8] Ch. Srinivas, B.V.Tirupanyam, A.Satish, V. Seshubai, D.L.Sastry, O.F.Caltun "Effect of $\mathrm{Ni}^{2+}$ substitution on structural and magnetic properties of $\mathrm{Ni}-\mathrm{Zn}$ ferrite nanoparticles" , J. Magn. Magn. Mater. 382(2015)1519.

[9] Ch.Srinivas, B.V.Tirupanyam, S.S.Meena, Ch.Seshu Babu, D.L.Sastry "Effect of Heat Treatment on Structural and Mössbauer Spectroscopic Properties of Co-precipitated $\mathrm{Mn}_{0.5} \mathrm{Ni}_{0.5} \mathrm{Fe}_{2} \mathrm{O}_{4}$ ferrite nanoparticles" AIP Conf. Proc. 1665, 050142-1-050142-3.

[10]H. M. Zaki, S. H. Al-Heniti, T. A. Elmosalami, J. Alloy. Compd. 633 (2015) 104-114.

[11] Santosh Bhukal, Rimi Sharma, Suman Mor, Sonal Singhal "Mg-Co-Zn magnetic nanoferrites: Characterization and their use for remediation of textile waste water" Superlattices and Microstructures 77(2015) 134-151.

[12]H. Mohseni, H. Shokrollahi, Ibrahim Sharifi, Kh. Gheisari "Magnetic and structural studies of the Mndoped $\mathrm{Mg}-\mathrm{Zn}$ ferrite nanoparticles synthesized by the

glycine nitrate process" J. Magn. Magn. Mater 324 (2012) 3741-3747.

[13] R. P. Patil, S. D. Delekar, D. R.Mane, P. P. Hankare "Synthesis, structural and magnetic properties of different metal ion substituted nanocrystalline zinc ferrite" Results in Physics 39(2013)129-133.

[14] Ch. Srinivas, B.V.Tirupanyam, S. S. Meena, S. M. Yusuf, Ch. SeshuBabu, K.S. Ramakrishna, D. M. Potukuchi, D. L. Sastry "Structural and magnetic characterization of co-precipitated $\mathrm{Ni}_{\mathrm{x}} \mathrm{Zn}_{1-\mathrm{x}} \mathrm{Fe}_{2} \mathrm{O}_{4}$ ferrite nanoparticles" J. Magn. Magn. Mater 407 (2016) 135141.

[15] Shaban I. Hussein, Ashraf S. Elkady, M. M. Rashad, A. G. Mostafa, R. M. Megahid "Structural and magnetic properties of magnesium ferrite nanoparticles prepared via EDTA-based sol-gel reaction" J. Magn. Magn. Mater. 379(2015) 9-15.

[16]A. Pradeep, P. Priyadharsini, G. Chandrasekaran "Strucutral, magnetic and electrical properties of nanocrystalline zinc ferrite" J. Alloy. Comp. 509(9) (2011) 3913-3923.

[17] Anjali Verma, Ratnamala Chatterjee "Effect of zinc concentration on the structural, electrical and magnetic properties of $\mathrm{Mn}-\mathrm{Zn}$ and Ni-Zn ferrites synthesized by the citrate precursor technique” J. Magn. Magn. Mater 306 (2006) 313-320.

[18] M. Rahimi, P. Kameli, M. Ranjbar, H. Hajihashemi, H. Salamati "The effect of zinc doping on the structural and magnetic properties of $\mathrm{Ni}_{1-\mathrm{x}} \mathrm{Zn}_{\mathrm{x}} \mathrm{Fe}_{2} \mathrm{O}_{4}$ " J. Mater. Sci 48 (2013) 2969-2976.

[19]B. V. Tirupanyam, Ch. Srinivas, S. S. Meena, S. M. Yusuf, A. SatishKumar, D. L. Sastry, V. Seshubai "Investigation of structural and magnetic properties of co-precipitated $\mathrm{Mn}-\mathrm{Ni}$ ferrite nanoparticles in the presence of $\alpha-\mathrm{Fe}_{2} \mathrm{O}_{3}$ phase" J. Magn. Magn. Mater 392 (2015) 101-106.

[20]Humaira Anwar, Asghari Maqsood "Structural, Magnetic and Electrical Properties of $\mathrm{Cu}$ Substituted Mn-Zn Soft Nanoferrites" J. Supercond. Nov. Magn 25 (6) (2012)1913-1920.

[21] Kumar Mohit, Vibha Rani Gupta, Nisha Gupta, S. K. Rout "Structural and microwave characterization of $\mathrm{Ni}_{0.2} \mathrm{Co}_{\mathrm{x}} \mathrm{Zn}_{0.8-\mathrm{x}} \mathrm{Fe}_{2} \mathrm{O}_{4}$ for antenna applications" Ceram. Int 40 (2014) 1575-1586.

[22] Tamara Slatineanu, Alexandra Raluca Iordan, Mircea Nicolae Palamaru, Ovidiu Florin Caltun, Vasilica Gafton, Liviu Leontie "Synthesis and characterization of nanocrystalline $\mathrm{Zn}$ ferrites substituted with Ni" Mater. Res. Bull. 46(2011) 1455-1460.

[23] M. A. Gabal, S. Kosa, T. S. Al Mutairi "Structural and magnetic properties of $\mathrm{Ni}_{1-\mathrm{x}} \mathrm{Zn}_{\mathrm{x}} \mathrm{Fe}_{2} \mathrm{O}_{4}$ nano-crystalline ferrites prepared via novel chitosan method" J. Molec.Strut. 1063 (2014) 269-273.

[24]P. Priyadharsini, A. Pradeep, P. Sambasiva Rao, G.Chandrasekaran "Structural, spectroscopic and magnetic studies of nanocrystalline $\mathrm{Ni}-\mathrm{Zn}$ ferrites" Mater. Chem. Phys. 116(1) (2009)207-213.

[25] M. Rahimi, P. Kameli, M. Ranjbar, H. Hajihashemi, H. Salamati "The effect of zinc doping on the structural and magnetic properties of $\mathrm{Ni}_{\mathrm{x}} \mathrm{Zn}_{1-\mathrm{x}} \mathrm{Fe}_{2} \mathrm{O}_{4}$ " J. Mater. Sci. 48(2013)2969-2976.

\section{Author Profile}

Volume 5 Issue 2, February 2016 


\section{International Journal of Science and Research (IJSR) \\ ISSN (Online): 2319-7064}

Index Copernicus Value (2013): 6.14 | Impact Factor (2014): 5.611

S. B. Singh received the B.Sc. and M.Sc. degrees in Physics from Andhra University. He published research papers in national and international journals. At present working as Senior Lecturer in Physics, A. P. Technical Education Services, A. P., India.

Dr. Ch. Srinivas received the B.Sc. and M.Sc. degrees in Physics and $\mathrm{Ph} . \mathrm{D}$ in Magnetic Materials from Andhra University. He published research papers in national and international journals. At present working as Professor in Physics, Sasi Institute of Technology and Engineering, A.P., India. 